\title{
BMJ
}

CHRISTMAS: YEARS LIKE THIS

\section{Ingested foreign bodies and societal wealth: three year observational study of swallowed coins}

\author{
P G Firth, instructor in anesthesia, Harvard Medical School, ${ }^{1} \mathrm{H}$ Zheng, assistant professor, Harvard Medical \\ School, ${ }^{2}$ J A Biller, assistant professor, Harvard Medical School ${ }^{3}$
}

'Anaesthetist, Department of

Anesthesia, Critical Care and Pain Medicine, Massachusetts General Hospital, 55 Fruit Street, Boston, MA 02114, USA

${ }^{2}$ Biostatistician, Biostatistics Center, Massachusetts General

Hospital, 50 Staniford Street, 5th Floor, Suite 560, Boston

${ }^{3}$ Gastroenterologist, Department of Gastroenterology, Mass General West, 40 Second Ave, Suite 340, Waltham, MA 02451, USA

Correspondence: P G Firth pfirth@partners.org

Cite this as: $B M J$ 2009;339:b5066 doi:10.1136/bmj.b5066

\section{ABSTRACT}

Objective To examine the relation between coins ingested by children and the Dow Jones Industrial Average.

Design Observational study.

Main outcome measures Total value of coins ingested and number of incidents of coins versus other objects swallowed, measured before and after the stock market crash of October 2008.

Results Eighteen objects, including 11 coins, were ingested (NASDAQ (numismatic and sundry detritus acquired) composite of 18). The total value of the 11 coins swallowed was $\$ 1.03$ (FTSE 100 (fraction of the US\$ or 100 cents) index of 103). The pecuniary extraction ratio (PE ratio) was 0.57 (9/16). Comparing values for a period before and after October 2008, the mean monthly NASDAQ composite ( 0.41 (SD 0.67) v 0.5 (0.85), $\mathrm{P}=0.75)$, FTSE 100 index in cents $(2.3(6.8) \vee 3.1(7.8), \mathrm{P}=0.77)$, and $\mathrm{PE}$ ratio $(0.54(0.52) v 0.66(0.29), \mathrm{P}=0.50)$ did not change. The mean end-of-month closing value of the Dow Jones, however, decreased significantly (12 537 (841.4) $v$ 8388 (699.8), P<0.001)

Conclusion There was no detectable difference in the total value of coins ingested, or ratio of coins to other objects swallowed, before or after a massive stock market crash.

\section{INTRODUCTION}

Aspiration and ingestion of foreign objects are well recognised problems in young children. ${ }^{1}$ One festive Australian toddler aspirated a plastic Christmas tree, ${ }^{2}$ while around Guy Fawkes Day British children prefer fireworks. ${ }^{3}$ The culinarily more sophisticated Italians reported an aspirated lobster antenna, ${ }^{4}$ while an adventurous American 2 year old staying at a roadside motel aspirated an unfortunate cockroach, which remained undetected for three days. ${ }^{5}$ Coins are a common foreign object swallowed by small children. ${ }^{6}$ Historically, the frank, mark, guilder, lira, drachma, and other currencies went down best in Europe, but the introduction of the euro saw a wave of new paediatric euroaspirants. $^{7-9}$ As the offending objects therefore reflect the environment, we hypothesised that the trickle down effect from the stock market, good or bad, would be reflected in what trickles down the paediatric oesophagus. We therefore examined the relation of coins ingested to the Dow Jones Industrial Average.

\section{METHODS}

After ensuring that our institutional review board had a well developed sense of humour, we compiled data on all numismatic and sundry detritus acquired (NASDAQ composite index) from children's gastrointestinal tracts by the paediatric gastroenterology service at our hospital between August 2006 and July 2009. We identified these from the computerised records of the endoscopy suite. No patients were excluded. We calculated the financial total swallowed and extracted as a fraction of the US\$ or 100 cents (FTSE 100 index), and the ratio of patients with coins versus all those with foreign objects removed (pecuniary extraction ratio, $\mathrm{PE}$ ratio). We calculated the mean end-of-month closing value of the Dow Jones Industrial Average. ${ }^{10}$ We examined whether there was a change in the monthly mean NASDAQ, FTSE, and $\mathrm{PE}$ ratio before and after the collapse of the Dow Jones Industrial Average of October 2008. We used a two sample $t$ test, assuming unequal variances.

\section{RESULTS}

The patients were aged 1 to 15 years. The NASDAQ composite index was 18 . Eleven coins were retrieved from nine patients: three pennies (or cents), five nickels ( 1 nickel $=5$ cents), no dimes ( 1 dime $=10$ cents), and three quarters ( 1 quarter $=25$ cents), giving a total return on ingestment for the period, or FTSE 100 index, of $\$ 1.03$. Seven other objects in seven children included an unsafe safety pin (open), a battery, a marble, a ballbearing, a magnet, a dentist's guard, and a rubber doorstopper. The PE ratio was therefore 0.57 (9/16). The table shows data before and after the stock market collapse.

\section{DISCUSSION}

We examined the value of coins ingested by children during a time of profound changes in the stock market valuation. We found no change in the FTSE 100 index 
(2.3 v 3.1, $\mathrm{P}=0.77)$ or $\mathrm{PE}$ ratio $(0.54 v 0.66, \mathrm{P}=0.5)$ during a period of dramatic alterations in Dow Jones (12 $537 v 8388, \mathrm{P}<0.0001)$, despite the NASDAQ composite index remaining stable $(0.4 v 0.5, \mathrm{P}=0.75)$. In other words, despite a massive swing in the stock market there was no concomitant absolute or relative change in paediatric wealth intake against an unaltered background rate of foreign body ingestion.

\section{Strengths and limitations}

We used a sensitive and well recognised marker of environmental conditions: the objects ingested by children. $^{1-57-9}$ Indeed, the validity of this model is illustrated by the fact that our $27 \%$ penny aspiration rate $(n=3 / 11)$ was lower than the $36 \%$ penny pinching rate reported in $1982 .{ }^{6}$ This is exactly as one would predict, given inflation rates over time. Our inability to detect a change in coin ingestion might, however, be credited to a unique confounder expected to influence both the risk factor (changes in stock market value) and the societal wealth marker (paediatric coin ingestion): the supply of credit. A reduction in credit supply will mean that, to meet household obligations, the use of

\begin{tabular}{|c|c|c|c|}
\hline $\begin{array}{l}\text { Objects ingested be } \\
\text { Values are means }\end{array}$ & $\begin{array}{l}\text { fore and after c } \\
\text { D) unless state }\end{array}$ & $\begin{array}{l}\text { llapse of sto } \\
\text { otherwise }\end{array}$ & market. \\
\hline Value & $\begin{array}{c}\text { Before } \\
\text { October } 2008\end{array}$ & $\begin{array}{l}\text { After October } \\
\quad 2008\end{array}$ & $P$ value \\
\hline $\begin{array}{l}\text { Dow Jones Industrial } \\
\text { Average }\end{array}$ & $12537(841.4)$ & $8388(699.8)$ & $<0.001$ \\
\hline $\begin{array}{l}\text { NASDAQ composite } \\
\text { index }\end{array}$ & 13 & 5 & - \\
\hline Monthly mean & $0.41(0.67)$ & $0.5(0.85)$ & 0.75 \\
\hline FTSE 100 index (US\$) & 0.72 & 0.31 & - \\
\hline Monthly mean (cents) & $2.3(6.8)$ & $3.1(7.8)$ & 0.77 \\
\hline PE ratio & $0.54(0.52)$ & $0.66(0.29)$ & 0.50 \\
\hline
\end{tabular}
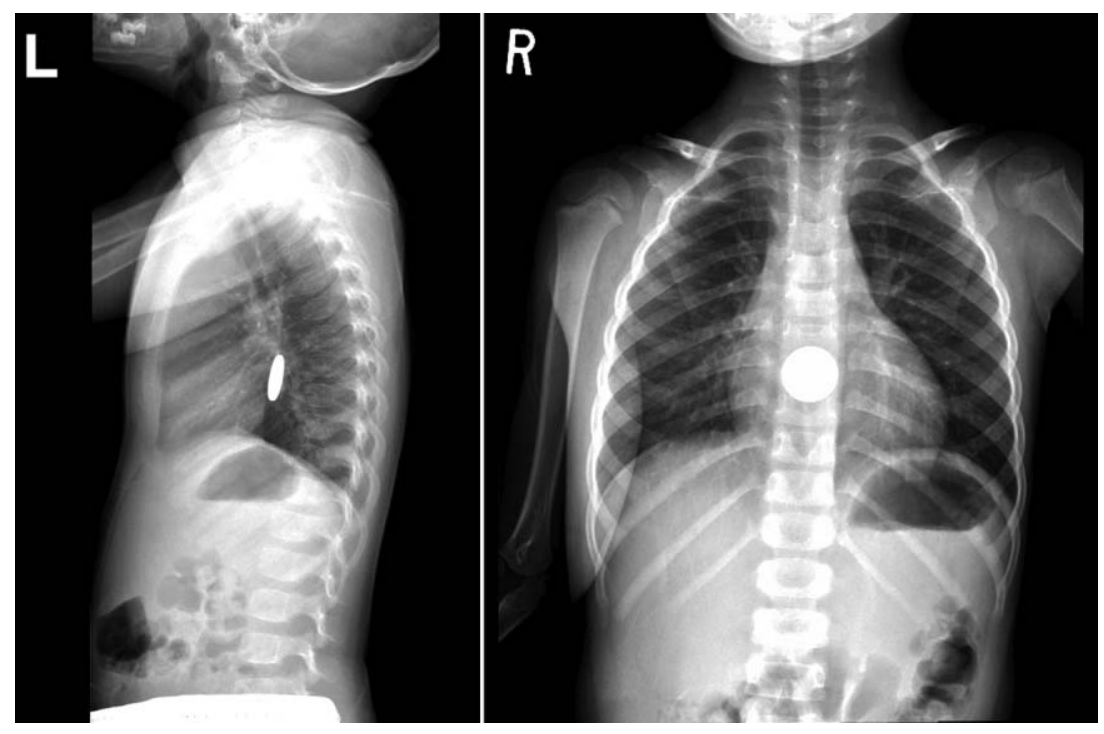

Fig $1 \mid X$ ray pictures can easily detect an ingested coin. Position of coin on lateral view (left), relative to anterior (right) or posterior picture affects size of image on film relatively difficult to ingest credit cards will be swapped for more palatable hard cash denomination. This credit denomination swap obligation could result in a paradoxical increase in the rate of paediatric wealth consumption, while lack of credit simultaneously restricts economic growth and depresses the stock market. This potential confounder might influence the risk factor and the societal wealth marker in opposite directions, hence masking a relation between them.

\section{Other studies}

Despite the thousands of articles about aerodigestive foreign bodies, there is surprising little gastropecuniary literature. This might be because of non-standardisation of numisluminal terminology and measurement. East of the Atlantic, the diphthong is widely used (oesophagus, aetiology, paediatric, for example), while on the western fringes (edema, anesthesia, humor, by illustration), its employment is typically limited to Miami Beach. The introduction of the euro brought a welcome standardisation of units of ingestion, at least in the eurozone. ${ }^{7-9}$

\section{Clinical practice}

The fate of an aspirated coin can be followed on $\mathrm{x}$ ray film. The asymptomatic child can be re-examined later to see if there is any change, but symptomatic coins or those lodged in the oesophagus need to be removed. The positioning of the $\mathrm{x}$ ray plate affects the image, ${ }^{11}$ such that, for example, an anterior-posterior view can produce an apparent increase in the size, and hence value, of deposits in the anterior abdomen (the Madoff effect) (fig 1). A small overestimation of the diameter of a penny can lead to the misassumption that it is a nickel (5c), or similarly that a nickel is a quarter (25c), a Madoff effect of $400 \%$ (fig 2). While this insider information might be marginally more reliable than a parliamentarian's expense account, this insight can be turned to good use when wagering on the value of the coin to be extracted. Parenthetically, before placing one's retirement funds on gastroesophaegal futures or derivatives, attention should be directed to the more proximal gastrointestinal tract to ensure the tongue is firmly in the cheek.

\section{Implications and future research}

An observational study cannot determine causality or even the direction of association. While we anticipated a change in coin ingestion related to the stock market, we did not set out to look for the reverse effect. A basic understanding of monetary theory is useful in ruminat ing on this. ${ }^{12}$ An economy's money supply has several definitions. In particular, the most basic definition, M0 (currency), refers to notes and coins in circulation and in bank vaults, while MB (the monetary base) also includes reserves that commercial banks hold with the central bank but have not loaned out. In turn, M1-M3 (various types of commercial bank money) are created through the fractional reserve system 


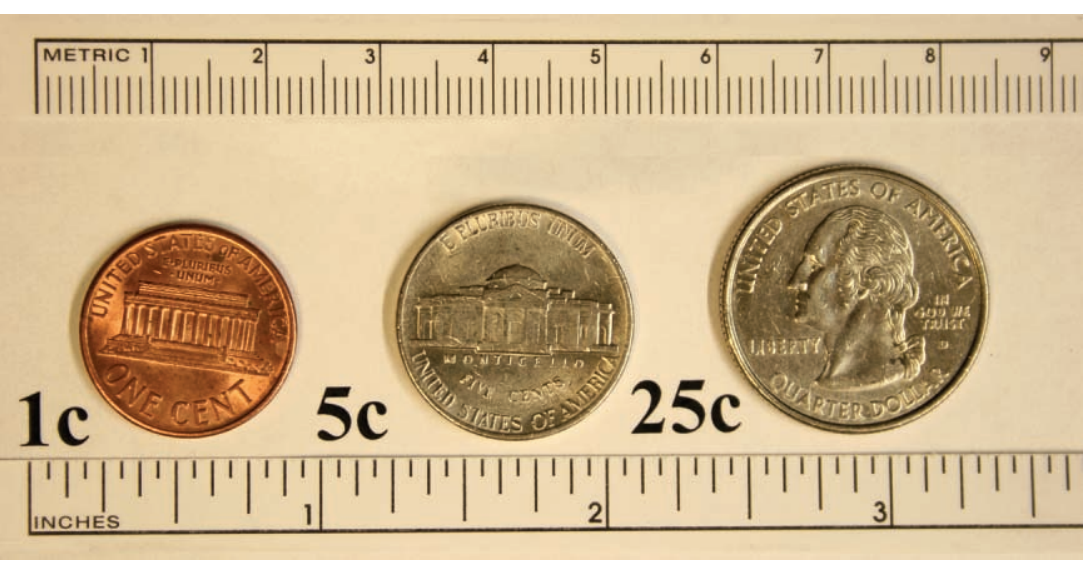

Fig 2 | Coin denominations extracted

\section{WHAT IS ALREADY KNOWN ON THIS TOPIC}

Small children often swallow coins

The stock market valuations have been extremely volatile in recent years

\section{WHAT THIS STUDY ADDS}

\section{Children decrease the M0 supply}

It is difficult to detect the plausible association between the value of the stock market and the value of coins children ingest

when a commercial bank makes a loan. For example, a commercial bank with $\$ 100$ deposit and a mandated $10 \%$ reserve can "create" $\$ 90$ of commercial money by loaning out $90 \%$ of the deposit. Thus, even small changes in the physical currency available might, under some circumstances, lead to disproportionately large changes in the broader measures of money supply and, in turn, overall economic activity. The realisation that major institutions did not have sufficient physical currency or reserves of central bank money to cover their debts in commercial money was a trigger for the credit crisis, prompting the central banks of various countries to transfer large amounts to commercial banks to prevent their collapse.

Chaos theory suggests that tiny differences in a starting state of a dynamic system can lead to massive changes in final outcome. ${ }^{13}$ This sensitivity, commonly known as the butterfly effect, can be amplified in an economy where transactions are increasingly performed entirely by computer,${ }^{14}$ producing exponential changes that give the impression of random or chaotic behaviour. Could small changes in the availability of small change caused by children eating into the M0 supply lead ultimately to a catastrophic imbalance of debt and collateral? As long as the inter-relation of microeconomic and macroeconomic conditions remains unclear, the possibility of the fluttering butterfly wings of paediatric piconomic perturbations leading to a global credit tornado must remain food for thought for gastroeconomists.

In conclusion, while our population, patients, and fiscal fluctuations might be small, the potential implications are huge. Further numismedical studies are urgently indicated to stress test these possibilities, perhaps funded by a tiny fraction of the government financial bailout and, ideally, conducted from tax havens favoured by the financial set, such as Monaco, Bermuda, or the Virgin Islands.

We thank Eric Brynjoffsen, MIT Sloan School of Management, for economic advice on monetary theory and why it is important to pay off your credit card; Elizabeth Hohmann of the Massachusetts General Hospital for humour in ethics; Scott Tolle of the Massachusetts General Hospital for clarity in imaging as usual; Allan Low, Gerry McCartney, and the $B M J$ editors for economic and epidemiological advice.

Contributors: PGF conceived the study and wrote the manuscript with input from $\mathrm{HZ}$ and JAB; $\mathrm{HZ}$ performed the statistical analysis; JAB provided details of the foreign bodies. PGF is guarantor.

Funding: Funding was obtained from the gastrointestinal tracts of our patients. Absolutely no taxpayer money was used for this research. Competing interests: The desires of the authors to earn Wall Street salaries conflict with their jobs in academic medicine.

Ethical approval: A member of the institutional review board of the Massachusetts General Hospital thoroughly approved of this study. Data sharing: No additional data available.

1 Rey M, Rey HA. Curious George goes to the hospital. 1st ed ed. Houghton Mifflin Books for Children, 1966.

2 Philip J, Bresnihan M, Chambers N. A christmas tree in the larynx. Paediatr Anaesth 2004;14:1016-20.

3 Morrison JB. Inhaled plastic cap from firework: report of two cases. BMJ 1966;ii:1052.

4 Tsagkaropoulos S, Francioni F, Ferretti G, Venuta F. An unusual case of foreign body aspiration: a lobster's antenna. Eur J Cardiothorac Surg 2009;36:185.

5 Marlow TJ, Schabel SI, Goltra DD Jr, Endobronchial cockroach: an unusual foreign body aspiration. J Emerg Med 1997;15:487-9.

6 Dorst JP, Reichelderfer TE, Sanders RC. Radiodensity of the proposed new penny. Pediatrics 1982;69:224-5.

7 Papadopoulos FC, Petridou E, Frangakis CE, Farmakakis T, Moller H, Rider G. Switching to the Euro: still hard to swallow. Arch Dis Child 2004;89:382-3.

8 Gill DG, Ryan S. Euroaspirations. Arch Dis Child 2004;89:795.

9 Saxena AK, Seebacher U, Baumann P, Kristler M. Introduction of the euro: the change is easily swallowed at a young age. Eur J Pediatr 2008;167:243-4.

10 Dow Jones Industrial Average $(\wedge \mathrm{DJI})$. Historical Prices for. http:// finance.yahoo.com/q/hp?s=\%5EDJl.

11 Cantu S Jr, Conners GP. The esophageal coin: is it a penny? Am Surg 2002;68:417-20.

12 Money Supply. http://en.wikipedia.org/wiki/Money_supply.

13 Chaos Theory. http://en.wikipedia.org/wiki/Chaos theory.

14 Brynjolfsson E, Saunders AS. Wired for innovation: how IT is reshaping the economy. 1st ed. MIT Press, 2010.

Accepted: 16 November 2009 